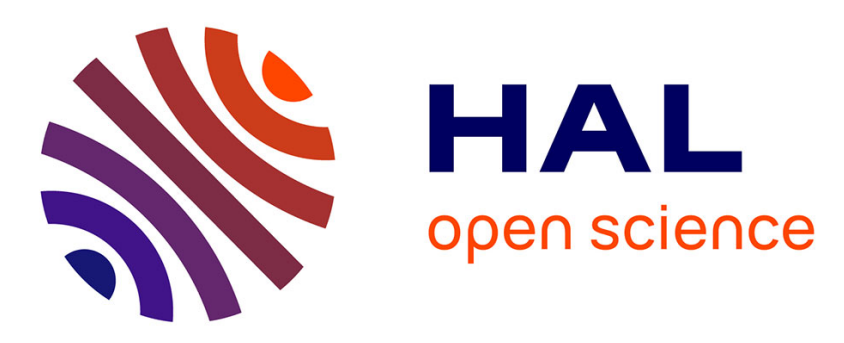

\title{
Efficacy and Safety of Surgery for Benign Prostatic Obstruction in Patients with Preoperative Urinary Catheter
}

Bastien Gondran-Tellier, Robin Mcmanus, Clement Sichez Pierre, Akram Akiki, Sarah Gaillet, Harry Toledano, Marc Andre, Veronique Delaporte, Vincent Vidal, Gilles Karsenty, et al.

\section{To cite this version:}

Bastien Gondran-Tellier, Robin Mcmanus, Clement Sichez Pierre, Akram Akiki, Sarah Gaillet, et al.. Efficacy and Safety of Surgery for Benign Prostatic Obstruction in Patients with Preoperative Urinary Catheter. Journal of Endourology and Part B, Videourology, 2021, 35 (1), pp.102-108. 10.1089/end.2020.0704 . hal-03165832

\section{HAL Id: hal-03165832 \\ https://hal-amu.archives-ouvertes.fr/hal-03165832}

Submitted on 15 Mar 2021

HAL is a multi-disciplinary open access archive for the deposit and dissemination of scientific research documents, whether they are published or not. The documents may come from teaching and research institutions in France or abroad, or from public or private research centers.
L'archive ouverte pluridisciplinaire HAL, est destinée au dépôt et à la diffusion de documents scientifiques de niveau recherche, publiés ou non, émanant des établissements d'enseignement et de recherche français ou étrangers, des laboratoires publics ou privés. 


\title{
Efficacy and Safety of Surgery for Benign Prostatic Obstruction in Patients with Preoperative Urinary Catheter
}

\author{
Bastien Gondran-Tellier ${ }^{1}$, Robin McManus ${ }^{1}$, Pierre Clement Sichez ${ }^{1}$, Akram Akiki ${ }^{1}$, Sarah \\ Gaillet ${ }^{1}$, Harry Toledano ${ }^{3}$, Marc Andre ${ }^{4}$, Veronique Delaporte ${ }^{1}$, Vincent Vidal ${ }^{4}$, Gilles \\ Karsenty ${ }^{1}$, Cyrille Bastide ${ }^{2}$, Dominique Rossi ${ }^{2}$, Eric Lechevallier ${ }^{1}$, Romain Boissier ${ }^{1}$, Michael \\ Baboudjian ${ }^{1}$
}

1. Dept. of Urology and Kidney Transplantation, Conception Academic Hospital, AixMarseille University, APHM, Marseille, France

2. Dept. of Urology, North Academic Hospital, Aix-Marseille University, APHM, Marseille, France

3. Dept. Of Urology, Martigues Hospital, Martigues, France

4. Dept. of Radiology and Medical imaging, La Timone Academic Hospital, AixMarseille University, APHM, Marseille, France / European Center for Medical Imaging Research CERIMED/LIIE

\section{Corresponding author:}

Bastien Gondran-Tellier

Bastien.GONDRAN@ap-hm.fr

$+33620011207$

Aix-Marseille University, APHM, Conception Academic Hospital, Dept. of Urology and Kidney Transplantation, Marseille, France

Word count:

Abstract: 250

Manuscript: 2202

Keywords: acute urinary retention; preoperative catheter; benign prostatic obstruction; enucleation; vaporization 
Abstract

Purpose: To evaluate the efficacy and safety of benign prostatic obstruction (BPO) surgery in patients with preoperative urinary catheterization.

Patients and Methods: We conducted a multi-institutional retrospective study including all patients who failed a trial without catheter (TWOC) after acute urinary retention (AUR) between January 2017 and January 2019. Patients with neurogenic bladder, prostate cancer or urethral stricture were excluded from the analysis. Patients underwent either monopolar/bipolar transurethral resection of the prostate (TURP), photoselective vaporization of the prostate (PVP), prostate artery embolization (PAE), open prostatectomy (OP) or endoscopic enucleation. The primary endpoint was 12-month urinary catheter free-survival without using benign prostatic hyperplasia (BPH)medications.

Results: One hundred and seventy one consecutive men (median age: 71 years; median prostate volume: $75 \mathrm{~cm}^{3}$ ) underwent BPO-surgery including 48 (28\%) TURP, 62 (36.3\%) PVP, 21 (12.3\%) endoscopic enucleation, 15 (8.8\%) PAE and 25 (14.6\%) OP. The median duration of preoperative urinary catheterization was 69 days (IQR 46-125). The twelvemonth urinary catheter free-survival rate was $84.8 \%(145 / 171)$. Satisfactory voiding returned to 121 patients (70.8\%). On backward stepwise multivariable analysis, PVP (OR 0.27[0.10-0.69]; $p=0.008$ ), PAE (OR 5.27[1.28-27.75]; $p=0.03$ ), endoscopic enucleation (OR $0.08[0-0.49] ; p=0.023$ ), OP (OR 0.10[0.01-0.57]; $p=0.034$ ), Charlson score (OR 1.36[1.141.66]; $p=0.001$ ) and number of preoperative TWOC failure (OR 2.53[1.23-5.51]; $p=0.014$ ) were significantly associated with catheter free-survival.

Conclusions: In this multi-institutional retrospective study including patients with preoperative catheterization, the overall success rate of BPO-surgery was $70.8 \%$ after oneyear follow-up. Compared to TURP, enucleation methods and PVP were associated with better catheter free-survival, while PAE was associated with higher risk of AUR recurrence. 
Introduction

Acute urinary retention (AUR) is one of the most common urological emergencies in the aging male population. More than $10 \%$ of men in their 70 's and a third of men in their 80 's are expected to be affected by this condition [1-2]. AUR is defined as a painful and palpable bladder, when the patient is unable to pass urine [3]. The etiology of AUR is thought to be multi-factorial, but is most commonly secondary to benign prostatic obstruction (BPO) [4]. Management of AUR consists of immediate bladder drainage by urethral catheterization. Evidence that urgent surgery after AUR is associated with high morbidity [5] has led to the generalized use of a trial without catheter (TWOC) [6-7]. Oral alfuzosin $10 \mathrm{mg}$ once daily increases the likelihood of successful TWOC and should be continued beyond the acute phase as it reduces the need for BPO surgery [8]. If the first TWOC fails, a second TWOC may be attempted one to two weeks later, but its effectiveness is limited [9].

In case of unsuccessful TWOCs, surgical intervention is considered to be the end point for AUR [10]. Monopolar transurethral resection of the prostate (TURP) has remained the cornerstone of BPO surgical treatment for more than nine decades. Over the past 20 years there have been considerable technological advancements in BPO procedures, and to date a wide range of surgical procedures is now available [11]. These alternative procedures include, bipolar TURB [12], Holmium laser enucleation (HoLEP) [13], photoselective vaporization of the prostate (VEP) [14] and prostatic artery embolization (PAE) [15]. The surgical outcomes for the treatment of AUR with failed TWOCs remain still undefined.

The aim of this multi-institutional study was to evaluate the efficacy and safety of BPO surgery in patients with preoperative catheterization who failed TWOCs after AUR.

\section{Materials \& Method}

\section{Study population}

Ethical approval was obtained from the Ethics Committee of the French Association of Urology (CERU_2019011). Consecutive patients who underwent BPO-procedures in La Conception Academic Hospital \& Nord Academic Hospital, Marseille, France, and 
Martigues Hospital, Martigues, France between January 2017 and January 2019 have been considered. The included population focused on patients with refractory urinary retention despite the use of $\alpha$-blocker and TWOC and who were eligible for BPO surgery. All patients had preoperative urinary catheter. Patients known to have neurogenic bladder, prostate cancer or urethral stricture were excluded from the analysis. Patients had at least 12 months clinical follow-up.

The baseline variables recorded included: patient age, body mass index (BMI), ageadjusted Charlson comorbidity index, antithrombotic therapy intake, PSA serum level $(\mathrm{ng} / \mathrm{ml})$, prostate volume $\left(\mathrm{cm}^{3}\right)$, prior BPH procedure, time between AUR and surgery (days) and number of failed TWOC.

\section{Desobstructive procedures}

Patients with AUR were catheterized and received once daily $\alpha$-blocker. The catheter was removed after at least two doses of $\alpha$-blocker. A TWOC was considered successful if the patient returned to satisfactory voiding without re-catheterization. If the first TWOC failed, successive TWOCs could be attempted one to two weeks later. All patients included had unsuccessful TWOC(s) and had a preoperative urinary catheter. Preoperative evaluations included digital rectal examination, urinary ultrasound, serum prostate-specific antigen (PSA), serum creatinine and urinary analysis including culture. In our centers, urodynamic studies were usually performed in well-selected patients (diabetes mellitus, radiotherapy or previous pelvic surgery, overactive bladder in the foreground) before BPO surgery. However, urodynamic testing in patients with an indwelling urinary catheter was difficult to perform due to the need to introduce clean intermittent self-catheterization in elderly patients. Therefore, urodynamic studies were often not performed or results were not available. Patients included in this study underwent either monopolar TURP, bipolar TURP, PVP using 180-W lasers, PAE, OP, HoLEP or GreenLight enucleation of the prostate (80-W laser, GreenLEP). Monopolar and bipolar TURP cases were combined into one treatment type, "TURP", as they provide very similar functional outcomes [16]. The registry also collected cases of HoLEP and GreenLEP procedures, and they were also combined into one treatment type, "Endoscopic Enucleation". The choice of surgical technique depended on 
prostate size, comorbidities, anesthesia concerns, patient preferences, available surgical equipment, and surgeon experience. The surgeons had various experience with BPO surgery. The only surgeon who performed HoLEP had experience with more than 170 procedures. The two surgeons who performed GreenLEP had experience with 30 procedures each. The radiologist had performed 110 PAE. OP, TURP and PVP surgeries have long been implemented in our centers and it is difficult to estimate the number of operations per surgeon. All the surgeons were well trained in these techniques. The surgical procedures were performed in a standardized fashion according to previously described techniques. After each procedure, a 20 or 22 French (Fr) 3-way transurethral catheter was inserted. Catheter removal was planned depending on the surgical procedure (24 to 48 hours following transurethral procedures, 5 to 7 days following OP, and 15 days following PAE).

\section{Follow-up and study endpoints}

Patients after BPO-procedures were reviewed four to six weeks after urethral catheter removal to evaluate treatment response and adverse events. If patients had symptomatic relief, further re-assessment at 6- and 12-months was scheduled.

The primary endpoint was 12-month urinary catheter free-survival without using BPH medications which was defined as a catheterization for a new episode of AUR in the 12 months following the surgical procedure. Secondary outcomes included: reoperation rate, safety of procedures which was evaluated according to the Clavien-Dindo classification of surgical complications [17], and analysis of in-hospital costs for each procedure. Detailed expense reports based on work records of activities and services performed by the medical and nursing staff, medical consumables used, medications administered, and costs for accommodation, rooms and equipment were provided by the accounts department of the hospital. These were used to compare in-hospital costs for each procedure. 


\section{Data analysis}

Demographic data, preoperative clinical information, perioperative and follow-up variables were recorded from the patients' medical files. Descriptive statistics were delineated for the available variables. Quantitative variables were reported in median, interquartile range [IQR] and analyzed using Kruskal-Wallis test. Categorical variables were described as numbers and percentages and were analyzed by Fisher's exact test. Backward stepwise multivariable logistic regression was used to identify predictive factors of BPH-procedures failure to successfully remove urinary catheters. Variables with $p<0.20$ in univariate analysis were considered to be included in a multivariate logistic regression model to calculate the adjusted ORs and $95 \% \mathrm{Cls}$. To detect multicollinearity, we calculated the Variance Inflation Factors (VIF) of each variable included in the model. Factors with VIF $>3$ were excluded. The area under the receiver operating characteristic (ROC) curve was used to evaluate the model discrimination. Statistical analyses were performed using R Version 3.5.3 (The R Foundation for Statistical Computing). For all tests a $p$ value of $<0.05$ was considered statistically significant.

\section{Results}

One hundred and seventy one consecutive men after TWOC failure following AUR underwent BPO-procedures between January 2017 and January 2019. The procedures performed included 48 (28\%) TURP, 62 (36.3\%) PVP, 21 (12.3\%) endoscopic enucleation, 15 (8.8\%) PAE and 25 (14.6\%) OP. The median follow-up was 14 (IQR 13-15) months. Completed 12 months of follow-up was achieved in all patients.

\section{Clinical and demographic characteristics}

Table 1 shows the baseline characteristics of the 171 patients. The median age was 72 years (IQR 65-80), the median PSA level was $5.3 \mathrm{ng} / \mathrm{mL}$ (IQR 2.9-9) and the median prostate volume was $75 \mathrm{~cm}^{3}$ (IQR 56-110). All patients had urinary retention and the median number of TWOCs failed was 2 (IQR 2-3). The median time between AUR and BPOprocedure was 69 days (IQR 46-125). 


\section{Efficacy of BPO procedures}

Urological outcomes after BPO-procedures are summarized in Table 2. Compared to TURP (6 [5-7] days), length of hospital stay was longer in the OP group (11 [10-12]; $p<0.001)$ and shorter in the PVP, endoscopic enucleation and PAE groups (5 [5-6] days; $p=0.002,3$ [3-3] days; $p<0.001$ and 3 [3-4] days; $p<0.001$, respectively). Postoperative success of catheter removal was achieved in 154 cases (90\%) with a lower success rate in the embolization group (53.3\%; $p<0.001)$. Twelve-month urinary catheter free-survival in the overall cohort was $84.8 \%$ (145/171) (Figure 1). Among them, 121 patients (70.8\%) returned to satisfactory voiding without postoperative use of BPH medications. Compared to TURP (60.4\%), urinary catheter free-survival without using BPH medications was higher in OP $(92 \% ; p=0.005)$ and endoscopic enucleation $(100 \% ; p<0.001)$ groups, similar in the PVP group (74.2\%; $p=0.15)$ and lower in the PAE group (13.3\%; $p=0.002)$.

Among the 26 patients who had recurrence of AUR, the reported reoperation rate up to 12 months post-procedure was $2.9 \%$ (5/171): three cases after PAE failure, one case after TURP failure, one case after PVP failure and no cases after OP or endoscopic enucleation ( $p$ $=0.01$ ). Two of these patients underwent endoscopic enucleation, one patient had TURP and one patient had PVP. All secondary therapies allowed catheter removal.

Patients who failed to remain without catheter despite surgery were most likely to be frailpatients (Table 1$)$. They were older $(p=0.006)$ with more comorbidities $(p<0.001)$ including cardiovascular diseases $(p=0.007)$. The number of preoperative TWOC failed was higher witnessing to a greater reluctance of surgeons to offer surgery to these patients. Interestingly, they didn't have a longer catheter dependency before the procedures or a higher prostate volume. On backward stepwise multivariable logistic regression analysis adjusted for variables with $p<0.20$ in univariate analysis, PVP (OR 0.27 [0.10-0.69]; $p=0.008$ ), PAE (OR 5.27 [1.28-27.75]; $p=0.03$ ), endoscopic enucleation (OR 0.08 [0-0.49]; $p=0.023$ ), OP (OR 0.10 [0.01-0.57]; $p=0.034$ ), Charlson score (OR 1.36 [1.14-1.66]; $p=0.001$ ) and the number of preoperative TWOC failure (OR 2.53 [1.23-5.51]; $p=0.014$ ) were significantly associated with catheter free-survival (Figure 2). The 
evaluation of the discrimination accuracy of our model using the area under receiveroperating characteristic curve was 0.843 , indicating high discrimination power.

\section{Postoperative complications}

Table 3 shows the 30-day postoperative complications classified according to the ClavienDindo grading system. There were significant differences concerning the overall complication rate between the five study groups $(p=0.002)$. Minor $(p=0.046)$ and major complications ( $p=0.027)$ were higher following OP. Major complications after OP included one hemorrhagic shock and two vesico-cutaneous fistulas requiring reoperation. One major episode of septic shock occurred after TURP.

\section{Cost analysis}

Compared to TURP (median: 6102€), costs of hospitalization were lower in PAE (median: 3837€), PVP (4303€) and endoscopic enucleation (3847€) groups $(p<0.001)$. No significant difference was found between PAE, PVP and endoscopic enucleation groups. Conversely, OP was associated with higher costs than TURP (7812€, $p=0.016)$.

\section{Discussion}

We performed a multi-institutional contemporary series of consecutive patients undergoing BPO procedures for refractory urinary retention despite the use of $\alpha$-blocker and TWOCs. Compared to the current literature, the novelty of this study was to evaluate outcomes of BPO-procedures only in patients who were preoperatively catheterized. Among the 171 patients included, the overall success rate of BPO procedures without postoperative use of $\mathrm{BPH}$-medication was approximatively $70 \%$ after one year. Taking into account the benefits and risks of each procedure, 180-W PVP and endoscopic enucleation appeared to be the best surgical approaches for removing urinary catheter and allowing satisfactory voiding in patients with a preoperative urinary catheter.

Our results confirm that enucleation methods performed better than TURP when either an open approach (OR 0.10 [0.01-0.57]) or laser energy (OR 0.08 [0-0.49]) were used. The fact that enucleation methods achieved the best outcomes compared with resection methods is not surprising, since enucleation removing more prostatic tissue [18]. However, despite 
the low failure rate and reoperation rate, OP was an invasive procedure, associated with more perioperative complications and longer hospital stay. The high incidence of perioperative morbidity of OP has prompted urologists to find less invasive treatment options that can reproduce the same functional results. In our study, endoscopic enucleation of the prostate achieved similar short- and medium-term efficacy to OP and had a more favorable perioperative safety profile. Currently, we recommend that OP could be proposed for men with prostates $>80 \mathrm{~mL}$ only if endourological equipment including a holmium laser or a bipolar system is not available. Conversely, the major drawback of the endoscopic enucleation procedures is a long and steep learning curve, preventing its widespread use throughout the urological community. Several studies have evaluated the learning curve for HoLEP and GreenLEP and have suggested that a range of $40-70$ cases is required to achieve a stable outcome level [19-21].

Given the rapid progression of the PVP technology over the last decade, there are limited long-term studies, and the current literature largely reports data from early $80-\mathrm{W}$ and $120-$ W systems [22-23]. A meta-analysis of four RCTs including 559 patients comparing PVP using the 80-W and 120-W lasers with TURP was performed in 2016 [24]. This study demonstrated no significant difference in functional and symptomatic parameters at 6-, 12-, and 24-month intervals when compared to TURP. However, the proportion of patients preoperatively catheterized was low, allowing no conclusion in this subgroup. Furthermore, the increase in power to $180 \mathrm{~W}$ has led to a faster and more efficient energy transfer that improves tissue removal [25]. Compared to TURP, 180-W PVP was significantly associated (OR 0.27 [0.10-0.69]) with catheter free-survival in our multivariate analysis. Patients undergoing PVP experienced a similar rate of adverse effects as compared with TURP patients, conferring a more favorable risk benefit in favor of PVP in patients with prolonged catheterization.

Compared to TURP, we showed that PAE (OR 5.27 [1.28-27.75]) was significantly associated with lower rate of catheter free-survival. Our results are in accordance with a previous study where TURP has a more pronounced, pure urodynamic desobstructive effect than PAE [26]. Endoscopic procedures should be preferred rather than PAE in 
patients with complications associated with bladder outlet obstruction such as repeated acute urinary retention with prolonged catheterization.

New techniques may be associated with an increased cost in terms of equipment and consumables use. However, these additional costs may be balanced by shorter hospital stay and other improvements in perioperative care. In accordance with a previous study from the French committee of lower urinary tract symptoms [27], we showed that PAE, PVP and HoLEP could be cheaper than TURP and OP due to their benefit regarding length of hospital stay [27]. Future studies are needed to evaluate long-term cost effectiveness of these techniques.

There are some limitations in this study. The retrospective design of this study presents inherent limitations. Longer term follow-up is required to fully realize the potential differences between both surgical treatments. Preoperative and postoperative symptoms index score (international prostate symptoms score [IPSS]) as well as uroflowmetry (Qmax and post-voiding residual) parameters were not available. This study included patients with prolonged bladder catheterization in whom these data were not assessable preoperatively, limiting comparisons. The indication for desobstructive surgery in older, frail-patients has to balance life expectancy, functional outcome, and surgical risk. Some of these patients were probably not included during the study period which could lead to selection bias. Minimally Invasive Surgical Therapy (MIST) is increasingly relevant as a large percentage of men who remain excluded from invasive surgery. Our series did not include some new methods for treating benign prostatic hyperplasia such as prostatic urethral lift, aquablation and water vapor thermal therapy. These MISTs as PAE could be considered as an alternative to conventional surgical treatments for catheter-dependent patients especially those at high anesthesia risk due to comorbidities.

\section{Conclusion}

In this multi-institutional retrospective study, approximatively $70 \%$ of patients with preoperative urinary catheters who underwent BPO surgery returned to satisfactory voiding without using BPH-medications after one year follow-up. Compared to TURP, enucleation methods and PVP were associated with better catheter free-survival while PAE 

was associated with higher risk of AUR recurrence. Further prospective randomized controlled trials are needed to confirm our results.

The authors declare no conflicts of interest. 


\section{References}

[1] Wei JT, Calhoun E and Jacobsen SJ: Urologic diseases in America project: benign prostatic hyperplasia. J Urol 2005; 173: 1256.

[2] Jacobsen SJ, Jacobson DJ, Girman CJ, Roberts RO, Rhodes T, Guess HA et al. Natural history of prostatism: risk factors for acute urinary retention. J Urol 1997; 158: 481-487.

[3] Abrams, P., et al. The standardisation of terminology of lower urinary tract function: report from the Standardisation Sub-committee of the International Continence Society. Neurourol Urodyn, 2002. 21: 167.

[4] Hallett JM, Stewart GD, McNeill SA. The management of acute urinary retention: treating the curse of the aging male. Curr Bladder Dysfunct Rep 2013; 8: 242-249.

[5] National Prostatectomy Audit Steering Group, R. Pickard, M. Emberton, D.E. Neal. The management of men with acute urinary retention. Br J Urol, 81 (1998), pp. 712-720

[6] M. Taube, H. Gajraj. Trial without catheter following acute retention of urine. BJU Int, 63 (1989), pp. 180-182

[7] S.A. McNeill et al. Sustained-release alfuzosin and trial without catheter after acute urinary retention: a prospective, placebo-controlled. BJU Int, 84 (1999), pp. 622-627

[8] McNeill SA, Hargreave TB, Roehrborn CG; Alfaur study group. Alfuzosin $10 \mathrm{mg}$ once daily in the management of acute urinary retention: results of a double-blind placebocontrolled study. Urology. 2005 Jan;65(1):83-9; discussion 89-90.

[9] Fitzpatrick JM, et al. Management of acute urinary retention: a worldwide survey of 6074 men with benign prostatic hyperplasia. BJU Int 2012; 109: 88-95.

[10] Flanigan RC, Reda DJ, Wasson JH, Anderson RJ, Abdellatif M, Bruskewitz RC. 5-year outcome of surgical resection and watchful waiting for men with moderately symptomatic benign prostatic hyperplasia: a Department of Veterans Affairs cooperative study. The Journal of urology. 1998; 160: 12-16; discussion 6-7. 
[11] Gratzke C et al. EAU Guidelines on the Assessment of Non-neurogenic Male Lower Urinary Tract Symptoms including Benign Prostatic Obstruction. Eur Urol. 2015 Jun;67(6):1099-1109.

[12] Mamoulakis, C., et al. Bipolar versus monopolar transurethral resection of the prostate for lower urinary tract symptoms secondary to benign prostatic obstruction. Cochrane Database Syst Rev, Protocol 2014.

[13] Yin, L., et al. Holmium laser enucleation of the prostate versus transurethral resection of the prostate: a systematic review and meta-analysis of randomized controlled trials. J Endourol, 2013. 27: 604.

[14] Thangasamy, I.A., et al. Photoselective vaporisation of the prostate using $80-\mathrm{W}$ and 120-W laser versus transurethral resection of the prostate for benign prostatic hyperplasia: a systematic review with meta-analysis from 2002 to 2012. Eur Urol, 2012. 62: 315.

[15] Ray, A.F., et al. Efficacy and safety of prostate artery embolization for benign prostatic hyperplasia: an observational study and propensity-matched comparison with transurethral resection of the prostate (the UK-ROPE study). BJU Int, 2018. 122: 270.

[16] Cornu JN, et al. A Systematic Review and Meta-analysis of Functional Outcomes and Complications Following Transurethral Procedures for Lower Urinary Tract Symptoms Resulting from Benign Prostatic Obstruction: An Update. Eur Urol. (2015) 67(6):1066-1096

[17] Clavien PA, Sanabria JR, Strasberg SM. Proposed classification of complications of surgery with examples of utility in cholecystectomy. Surgery 1992;111:518-526.

[18] Placer J, Gelabert-Mas A, Vallmanya F, et al. Holmium laser enucleation of prostate: outcome and complications of self-taught learning curve. Urology 2009;73:1042-8.

[19] Robert G, Cornu JN, Fourmarier M, et al. Multicentre prospective evaluation of the learning curve of holmium laser enucleation of the prostate (HoLEP). BJU Int 2016; 117:495-499. 
[20] Misrai V, Faron M, Guillotreau J, et al. Assessment of the learning curves for photoselective vaporization of the prostate using GreenLight 180-Watt-XPS laser therapy: Defining the intra-operative parameters within a prospective cohort. World J Urol 2014;32:539-544.

[21] Peyronnet B, Robert G, Comat V, et al. Learning curves and perioperative outcomes after endoscopic enucleation of the prostate: A comparison between GreenLight 532-nm and holmium lasers. World J Urol 2017;35:973-983.

[22] I.A. Thangasamy, V. Chalasani, A. Bachmann, H.H. Woo. Photoselective vaporisation of the prostate using $80-\mathrm{W}$ and $120-\mathrm{W}$ laser versus transurethral resection of the prostate for benign prostatic hyperplasia: a systematic review with meta-analysis from 2002 to 2012 . Eur Urol, 62 (2012), pp. 315-323

[23] H. Ding, W. Du, Z.P. Lu, Z.X. Zhai, H.Z. Wang, Z.P. Wang. Photoselective green-light laser vaporisation vs. TURP for BPH: meta-analysis. Asian J Androl, 14 (2012), pp. 720-725

[24] Zhou, Y., et al. Greenlight high-performance system (HPS) 120-W laser vaporization versus transurethral resection of the prostate for the treatment of benign prostatic hyperplasia: a meta-analysis of the published results of randomized controlled trials. Lasers Med Sci, 2016. 31: 485.

[25] M. Rieken, G. Bonkat, G. Muller, et al. The effect of increased maximum power output on perioperative and early postoperative outcome in photoselective vaporization of the prostate. Laser Surg Med, 45 (2013), pp. 28-33

[26] Abt, D., et al. Comparison of prostatic artery embolisation (PAE) versus transurethral resection of the prostate (TURP) for benign prostatic hyperplasia: randomised, open label, non-inferiority trial. BMJ, 2018. 361: k2338.

[27] R Mathieu, S Lebdai, J N Cornu, et al. Perioperative and economic analysis of surgical treatments for benign prostatic hyperplasia: A study of the French committee on LUT. Prog Urol. 2017 May;27(6):362-368. 
Acute urinary retention (AUR)

Benign prostatic obstruction (BPO)

Trial without catheter (TWOC)

Transurethral resection of the prostate (TURP)

Holmium laser enucleation (HoLEP)

Photoselective vaporization of the prostate (VEP)

Prostatic artery embolization (PAE)

Body mass index (BMI)

Benign prostatic hyperplasia (BPH) 
Table 1 - Baseline characteristics

\begin{tabular}{|c|c|c|c|c|}
\hline & $\begin{array}{l}\text { Overall cohort } \\
\qquad(n=171)\end{array}$ & $\begin{array}{l}\text { Success } \\
\text { group } \\
(n=124)\end{array}$ & $\begin{array}{l}\text { Failure group } \\
\qquad(n=47)\end{array}$ & $\mathbf{p}$ \\
\hline Median (IQR) age, years & $72(65-80)$ & 71 (64-79) & $77(70-82)$ & 0.006 \\
\hline $\begin{array}{l}\text { Median (IQR) Body Mass } \\
\text { Index }\end{array}$ & $24.7(23-27.3)$ & $24.4(23-27)$ & $25(22.6-28)$ & 0.76 \\
\hline Median (IQR) Charlson score & $4(3-6)$ & $3(2-5)$ & $5(4-7)$ & $<0.001$ \\
\hline Antithrombotic, $n$ (\%) & $81(47.4)$ & $51(41.1)$ & $30(63.8)$ & 0.007 \\
\hline $\begin{array}{l}\text { Median (IQR) serum PSA level, } \\
\mathrm{ng} / \mathrm{ml}\end{array}$ & $5.3(2.9-9)$ & $5.9(3.1-9.3)$ & $5(2.5-7.5)$ & 0.34 \\
\hline $\begin{array}{l}\text { Median (IQR) prostate } \\
\text { volume, } \mathrm{cm}^{3}\end{array}$ & $75(56-110)$ & $81(50-120)$ & $66(48-92)$ & 0.01 \\
\hline Prior BPO procedure, $n$ (\%) & $8(4.7)$ & $5(4)$ & $3(6.3)$ & 0.68 \\
\hline $\begin{array}{l}\text { Median (IQR) preoperative } \\
\text { catheterization time, days }\end{array}$ & $69(46-125)$ & $67(45-118)$ & 79 (51-149) & 0.26 \\
\hline $\begin{array}{l}\text { Median (IQR) number of } \\
\text { TWOC }\end{array}$ & $2(2-3)$ & $2(2-3)$ & $2(2-3)$ & 0.01 \\
\hline
\end{tabular}

Legend: PSA: Prostate Specific Antigen; BPO: Benign Prostatic Obstruction; TWOC: Trial Without Catheter 
Table 2 - Perioperative and Long Term Clinical Outcomes

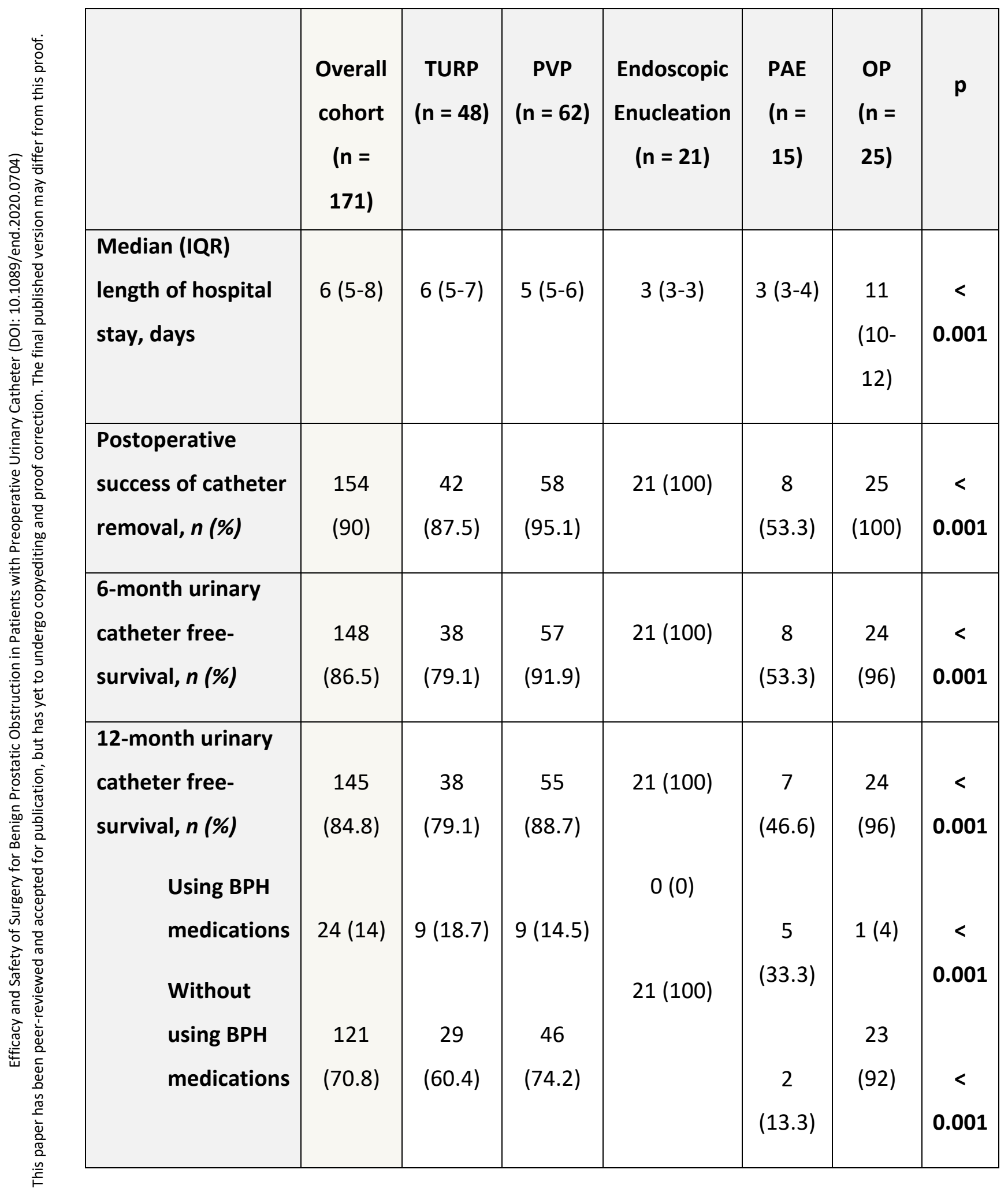


Legend:

TURP: Transurethral Resection of the Prostate; PVP: Photoselective Vaporization of the

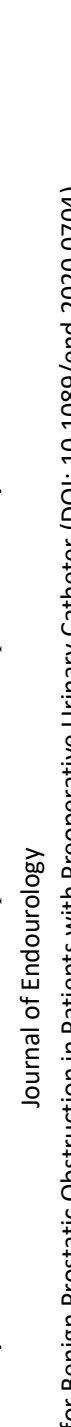
Prostate; PAE: Prostate Artery Embolization; OP: Open Prostatectomy; TWOC: Trial Without Catheter 
Table 3 - Overall 30 Day Postoperative Complications Classified According to Clavien-

Dindo Grading System

\begin{tabular}{|c|c|c|c|c|c|c|c|}
\hline & $\begin{array}{c}\text { Overall } \\
\text { cohort } \\
\text { (n= } \\
171)\end{array}$ & $\begin{array}{l}\text { TURP } \\
\text { (n= } \\
48)\end{array}$ & $\begin{array}{l}\text { PVP } \\
(n= \\
62)\end{array}$ & $\begin{array}{l}\text { Endoscopic } \\
\text { Enucleation } \\
\qquad(\mathbf{n}=\mathbf{2 1})\end{array}$ & $\begin{array}{l}\text { PAE } \\
(n= \\
15)\end{array}$ & $\begin{array}{l}\text { OP } \\
(n= \\
25)\end{array}$ & $p$ \\
\hline $\begin{array}{l}\text { Overall } \\
\text { postoperative } \\
\text { complications, } \mathrm{n} \\
\text { (\%) } \\
\text { None } \\
\text { At least one } \\
\text { complication }\end{array}$ & $\begin{array}{c}120 \\
(70.2) \\
51 \\
(29.8)\end{array}$ & $\begin{array}{l}35(73) \\
13(27)\end{array}$ & $\begin{array}{l}50(81) \\
12(19)\end{array}$ & $\begin{array}{l}16(76) \\
5(24)\end{array}$ & $\begin{array}{l}10(67) \\
5(33)\end{array}$ & $\begin{array}{l}9(36) \\
16(64)\end{array}$ & 0.002 \\
\hline Grade 1-2, n (\%) & $\begin{array}{c}47 \\
(27.5)\end{array}$ & $12(25)$ & $12(19)$ & $5(24)$ & $5(33)$ & $13(52)$ & 0.046 \\
\hline Grade $\geq 3, n(\%)$ & $4(2.3)$ & $1(2)$ & $0(0)$ & $0(0)$ & $0(0)$ & $3(12)$ & 0.027 \\
\hline
\end{tabular}

Legend:

TURP: Transurethral Resection of the Prostate; PVP: Photoselective Vaporization of the Prostate; PAE: Prostate Artery Embolization; OP: Open Prostatectomy 


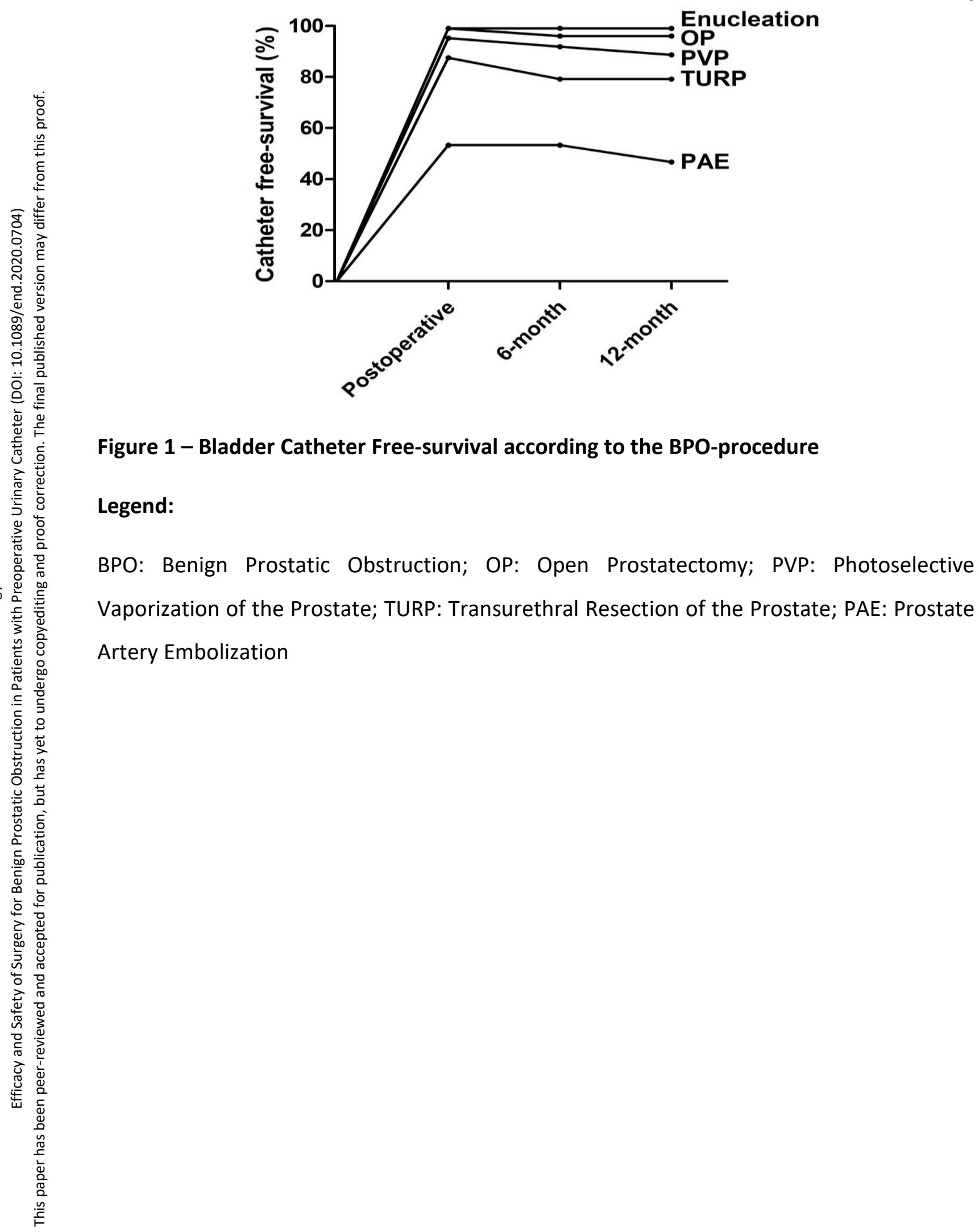




\begin{tabular}{|c|c|c|c|c|c|}
\hline Variable & $\mathbf{N}$ & \multicolumn{2}{|c|}{ Odds ratio } & & $\mathbf{p}$ \\
\hline \multicolumn{2}{|l|}{ Procedure } & & & & \\
\hline TURP & 48 & \multicolumn{2}{|c|}{ 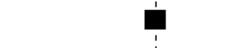 } & \multicolumn{2}{|l|}{ Reference } \\
\hline PVP & 62 & $1=$ & & $0.27(0.10,0.69)$ & 0.008 \\
\hline PAE & 15 & & $1=-1$ & $5.27(1.28,27.75)$ & 0.030 \\
\hline Endoscopic Enucleation & 21 & $\longmapsto \square$ & & $0.08(0.00,0.49)$ & 0.023 \\
\hline OP & 25 & $\longmapsto \square-1$ & & $0.10(0.01,0.57)$ & 0.034 \\
\hline Charlson Score & 171 & & ב & $1.36(1.14,1.66)$ & 0.001 \\
\hline Number of TWOC & 171 & & $\mathbf{a r}$ & $2.53(1.23,5.51)$ & 0.014 \\
\hline
\end{tabular}

Figure 2 - Forest plot of the Odds Ratios with 95\% Confidence Intervals Based on Different Covariates Included in Multivariate Analysis

\section{Legend}

TURP: Transurethral Resection of the Prostate; PVP: Photoselective Vaporization of the Prostate; PAE: Prostate Artery Embolization; OP: Open Prostatectomy; TWOC: Trial Without Catheter 